\title{
Flexible Ureterorenoscopy and Robotic Surgery
}

\author{
Erdal Alkan, MD, Oguz Ozkanli, MD, Mevlana Derya Balbay, MD \\ Department of Urology, Memorial Șișli Hospital, Okmeydanı, Șișli-; Istanbul, Turkey (Drs. Alkan, Balbay). \\ Department of Anesthesiology, Memorial Șișli Hospital, Okmeydanı, Șișli-; Istanbul, Turkey (Dr. Ozkanli).
}

\begin{abstract}
Introduction: We present the feasibility of flexible ureteroscopic lithotripsy concomitant with robot-assisted radical prostatectomy and bilaterally extended pelvic lymphadenectomy.

Methods: Two patients underwent flexible ureteroscopic lithotripsy, robot-assisted radical prostatectomy, and pelvic lymphadenectomy at one anesthesia session. Flexible ureteroscopic lithotripsy was performed first. Later, robotic prostatectomy and lymphadenectomy were performed with the patient in the exaggerated $30^{\circ}$ Trendelenburg position. All relevant preoperative clinical details, intraoperative details, problems encountered, complications, hospital stay, postoperative recovery, pathologic findings, and clinical follow-up were assessed.

Results: Both patients were discharged uneventfully from the hospital on the third postoperative day. In the postoperative first month, the double-J stents were removed. Both patients were prescribed hormonal treatment and were also referred for radiotherapy due to final pathology and postoperative prostate-specific antigen levels.
\end{abstract}

Conclusion: Combining robot-assisted radical prostatectomy and flexible ureteroscopy is feasible in patients with urinary stone disease and prostate cancer concomitantly.

Key Words: Flexible ureterorenoscopy, Urolithiasis, Robotic surgery, Prostate cancer, One anesthesia session.

Citation Alkan E, Ozkanli O, Balbay MD. Flexible ureterorenoscopy and robotic surgery. CRSLS e2014.00107. DOI: 10.4293/CRSLS.2014.00107.

Copyright (C) 2014 SLS This is an open-access article distributed under the terms of the Creative Commons Attribution-Noncommercial-ShareAlike 3.0 Unported license, which permits unrestricted noncommercial use, distribution, and reproduction in any medium, provided the original author and source are credited.

Address correspondence to: Erdal Alkan, MD, Memorial Şişli Hospital, Department of Urology, Okmeydanı, 34385 Şişli-; Istanbul, Turkey. Telephone: (+90)

212-314-6666, Fax: (+90) 212 -314-6608, E-mail: eralkan@hotmail.com

\section{INTRODUCTION}

Urinary stones are one of the most common conditions that affect the kidneys, ${ }^{1}$ and the lifetime risk of urolithiasis in the general population is $13 \%$ in men and $7 \%$ in women. ${ }^{2}$ Although there are various treatment modalities such as percutaneous nephrolithotomy, shock wave lithotripsy, open surgery, and ureteroscopic lithotripsy for kidney stone disease, retrograde intrarenal surgery with flexible ureteroscope has been found recently to have a good success rate for the management of renal stones.

Prostate cancer (PCa) is the most common male cancer in developed countries ${ }^{3}$ and can be completely treatable when it is organ confined. In this stage, the most preferred treatment is radical prostatectomy (RP). Open RP, laparoscopic RP, and robot-assisted RP are surgical options for the management of localized PCa. Herein, we report 2 patients with left kidney stones and localized PCa who underwent left flexible ureterorenoscopic lithotripsy
(FURS-L), robot-assisted radical prostatectomy (RARP), and robot-assisted bilateral pelvic lymphadenectomy (RABPL) at one anesthesia session.

\section{MATERIALS AND METHODS}

Between February 2012 and September 2012, 2 patients with PCa and left kidney stones were admitted to our clinic. Biochemical tests including kidney function tests, hemogram, alanine aminotransferase, aspartate aminotransferase, and alkaline phosphatase all demonstrated normal limits in both patients. Because of their elevated prostate-specific antigen (PSA), levels both patients were investigated with bone scintigraphy and abdominopelvic computed tomography (CT) scans for staging purposes (Table 1). The CT scans showed concomitant left kidney stones in addition to localized PCa. Patients were informed of their stone disease and its complications, as well as treatment options, including FURS-L, and both 
Table 1.

Preoperative Features of the Patients

\begin{tabular}{|c|c|c|c|c|c|c|c|c|}
\hline Patient & $\begin{array}{l}\text { Age } \\
(y)\end{array}$ & DRE & $\begin{array}{l}\text { Prostate } \\
\text { Volume }\end{array}$ & $\begin{array}{l}\text { PSA } \\
(\mathrm{ng} / \mathrm{mL})\end{array}$ & Biopsy & CT & $\begin{array}{l}\text { ASA } \\
\text { Score }\end{array}$ & $\begin{array}{l}\mathrm{BMI} \\
\left(\mathrm{kg} / \mathrm{m}^{2}\right)\end{array}$ \\
\hline P1 & 60 & $\begin{array}{l}\text { Grade III prostate with } \\
\text { an indurated left lobe }\end{array}$ & $100 \mathrm{~mL}$ & 84 & $\begin{array}{l}\text { Gleason score } 4+3 \\
\text { (tumor present in } \\
10 \text { of } 12 \text { core) }\end{array}$ & $\begin{array}{l}\text { In midpole } 9 \mathrm{~mm} \text {, and in } \\
\text { lower pole } 5 \mathrm{~mm} \text { and } 4 \\
\text { mm stones }\end{array}$ & II & 32 \\
\hline P2 & 53 & $\begin{array}{l}\text { Grade I benign } \\
\text { prostate }\end{array}$ & $30 \mathrm{~mL}$ & 12 & $\begin{array}{l}\text { Gleason score } 3+4 \\
\text { (tumor present in } \\
\text { the left side, } 5 \text { of } 6 \\
\text { core ) }\end{array}$ & $\begin{array}{l}\text { In the renal pelvis } 15 \\
\mathrm{~mm} \text { and } 12 \mathrm{~mm} \text { and in } \\
\text { lower pole } 9 \mathrm{~mm} \text { stones }\end{array}$ & II & 29 \\
\hline
\end{tabular}

ASA = American Society of Anesthesiologists (score); BMI = body mass index; DRE = digital rectal examination.

Table 2.

Pathologic Results of the Patients

\begin{tabular}{llllll}
\hline Patient & $\begin{array}{l}\text { Gleason } \\
\text { Score }\end{array}$ & Tumor Position & Tumor Volume & $\begin{array}{l}\text { Surgical } \\
\text { Margin }\end{array}$ & Biopsy 2 \\
\hline P1 & $4+3$ & $\begin{array}{l}\text { Tumoral invasion was } \\
\text { present in the left } \\
\text { seminal vesicle }\end{array}$ & $29 \mathrm{~cm}^{3}(29 \%)$ & Negative & $\begin{array}{l}\text { Bilaterally pelvic lymph node } \\
\text { metastasis (right: } 1 / 14,3 \mathrm{~mm} \\
\text { left: } 1 / 7,5 \mathrm{~mm})\end{array}$ \\
P2 & $3+4$ & $\begin{array}{l}\text { Extra prostatic } \\
\text { extension was } \\
\text { present }\end{array}$ & $3.5 \mathrm{~cm}^{3}(12 \%)$ & Negative & $\begin{array}{l}\text { No pelvic lymph node } \\
\text { metastasis (right: } 0 / 23, \text { left: } \\
0 / 11)\end{array}$ \\
\hline
\end{tabular}

patients decided to undergo RARP and RABPL at one anesthesia session.

FURS-L was planned and an access sheath (12Fr-14Fr$35 \mathrm{~cm}$ ) was placed in the left side with the patient in the lithotomy position. Next, the kidney stones were broken down using a 9-Fr flexible ureterorenoscope and holmium laser. Small pieces of stones were extracted with an Ngage extractor, followed by placement of a $4.8-\mathrm{Fr} 26-\mathrm{cm}$ double-J stent (DJS) in the ureter. Having completed the FURS-L, the patient's position was changed from lithotomy to an exaggerated $30^{\circ}$ Trendelenburg position. Robotic trocars were placed at the appropriate sites and the robotic arms were docked. First, a transperitoneal nonnerve-sparing RARP was performed in both patients. In addition to RARP, extended RABPL was performed in both patients, and lymphatic tissue around the common iliac and external iliac arteries and the common iliac and external iliac veins, and the obturator nerve, were all removed.

All relevant preoperative clinical details, body mass index, intraoperative details and problems encountered, surgical and anesthesia time, blood loss, complications, hospital stay, postoperative recovery, pathologic findings, and clinical follow-up were assessed.

\section{RESULTS}

The preoperative features of the 2 patients who underwent FURS-L, RARP, and RABPL are shown in Table $\mathbf{1 .}$

The FURS time for Patient 1 (P1) and Patient 2 (P2) were 55 and 85 minutes, respectively. During the procedures, all pieces of small stones were carefully removed. The console times in the robotic surgery for P1 and P2 were 215 and 165 minutes, respectively. There were no intraoperative complications. For pain control during the postoperative period, both patients were given narcotic analgesic via intravenous patient-controlled analgesia. Kidneyureter-bladder radiographs revealed appropriately placed DJS in the left ureters of both patients, with no residual stone fragments. The drain was removed on the third postoperative day and the patients were discharged home on the same day in good condition with minimal pain. After negative cystogram results were found to be negative, the Foley catheters were removed in P1 and P2 on postoperative days 7 and 10, respectively. The pathologic results of both patients are summarized in Table 2 . 
In the postoperative first month, the PSA levels for P1 and $\mathrm{P} 2$ were $0.16 \mathrm{ng} / \mathrm{mL}$ and $0.12 \mathrm{ng} / \mathrm{mL}$, respectively, and DJS were removed. Both patients were prescribed hormonal treatment and also referred for radiotherapy as a result of final pathology and postoperative PSA levels.

\section{DISCUSSION}

Nephrolithiasis and PCa are the most commonly encountered diseases in urology. With advancement in the technology of fiber optics and the production of smaller-caliber endoscopes, use of flexible ureteroscopy has recently been gradually increased in the management of kidney stones. Likewise, RP has become the most commonly performed robot-assisted surgery in the United States. Although there are many operations performed with robotic surgery that are reported in the English literature, ${ }^{4-6}$ there has not been any case of surgery performed in conjunction with FURS-L. To our knowledge, this is the first report published in the English literature in which patients underwent RARP, RABPL, and FURS-L during the same session.

With increased experience, the operation time using flexible ureteroscopy and a robotic system has gradually decreased, and in cases where prostate cancer and urolithiazis diagnosed concomittantly, combined surgeries have come into question. The primary concerns for a combined procedure are multifactorial and include patient safety, technical difficulty, and length of the procedures. ${ }^{6}$ In our cases, we did not encounter any difficulties. Of note, ureteral dilatation and DJS placement did not impose any difficulty or result in ureteric injury at the time of lymph node dissection, where both ureters are stripped for complete lymph node removal. In addition, preplacement of a DJS helps to identify the ureteral orifice at the time of bladder neck dissection during RARP.

The American Society of Anesthesiologists score in our 2 patients was 2, but the risks of prolonged robotassisted laparoscopic surgery in patients with American Society of Anesthesiologists higher than grade 2 are still not certain, and extreme caution must be taken before proceeding with the second concomitant surgery in this group. ${ }^{6}$
There are some advantages of simultaneous intervention, including having only a single anesthesia session, shorter hospital stay, less medication, reduced psychological stress, and respectable cost-effectiveness. For select patients, a combined procedure may minimize total anesthesia time and recuperation time, as well as the inconvenience of enduring multiple hospital admissions.

\section{CONCLUSION}

RARP can be performed safely in patients with urinary stone disease who require endoscopic stone removal with ureteroscopy. Ureteric dilatation and manipulation at this time did not seem to impose any significant risk on ureteric dissection or increase the risk of ureteral injury at the time of lymph node dissection, where the ureters are stripped for complete lymph node removal. However, much larger series are needed to conclude that RP and flexible ureteroscopy can be done safety without increasing any complication related to these surgeries alone or to the anesthesia procedure.

\section{References:}

1. Johnston WK 3rd, Low RK, Das S. The evolution and progress of ureteroscopy. Urol Clin North Am. 2004;31:5-13.

2. Argyropoulos AN, Tolley DA. SWL is more cost-effective than ureteroscopy and Holmium: YAG laser lithotripsy for ureteric stones: a comparative analysis for a tertiary referral centre. Br J Med Surg Urol. 2010;3:65-71.

3. Boyle P, Ferlay J. Cancer incidence and mortality in Europe 2004. Ann Oncol. 2005;16:481-488.

4. Patel MN, Eun D, Menon M, Craig G. Rogers. Combined robotic-assisted laparoscopic partial nephrectomy and radical prostatectomy. JSLS. 2009;13:229-232.

5. Akbulut Z, Canda AE, Cimen HI, Atmaca AF, Korukluoglu B, Balbay MD. Two procedures at the same robotic session: robotassisted laparoscopic radical prostatectomy and cholecystectomy. Surg Laparosc Endosc Percutan Tech . 2011;21(1):34-35.

6. Nayyar R, Gupta NP, Hemal AK, Kumar R. Two concomitant robot-assisted procedures in one anesthesia session: our experience. J Endourol. 2009;23(2):263-267. 